
D:\Nsurg\Vol. 24, No. 1, Jan. - Mar., 2020\Nsurg-1.Doc
Fig. 1 Color
(A)
P. $51-55$
III

ORIGINAL ARTICLE

\title{
Outcome of Retinaculotomy for Carpal Tunnel Syndrome
}

\author{
GOHAR ALI, ASGHAR ALI, MUKHTIAR ALI, NAEEM-UL-HAQ, SALMAN MUKHTAR \\ Department of Neurosurgery, Bacha Khan Medical College and MTI Mardan Medical Complex, KPK - Pakistan \\ DOI: 10.36552/pjns.v24i1.399
}

\begin{abstract}
Objective: To evaluate the results of a minimally invasive technique performed for the most prevalent disease which is not dependent on sophisticated instrumentation and results in early return to work.
\end{abstract}

Material and Methods: A total of 52 patients was operated and included in the study. The record of these patients was collected on specified proforma. We used the retinaculotomy method performed by 3 surgeons of the same competence level.

Results: Total number of patients operated was 52 Male 8 (15\%) Female 44 (85\%). A total of 48 (92\%) patients improved (by $4^{\text {th }}$ week in terms of VAS from 6 to 1 or 0$) .9 \%$ of patients had scar tenderness which improved by $4^{\text {th }}$ week in $100 \%$ patients. Almost all the patients resumed their daily life activities by $4^{\text {th }}$ week.

Conclusion: It was concluded from this study that using the mini technique of retinaculotomy the complications associated with the use of the classic open technique can be avoided and patients successfully treated can have an early return to their normal daily life activities.

Keywords: Retinaculotomy, Carpal Tunnel Syndrome, Mini Technique Carpal Tunnel, Phalen's Sign, Nerve Conduction Study.

\section{INTRODUCTION}

Carpal tunnel syndrome is one of the many prevalent nerve entrapment disorders, especially common amongst married women. This disorder is also found in those men who use their wrist joints repetitively like typists, carpenters mechanics, milkmen etc. The symptoms include numbness and pain in the lateral 3 and half fingers of the hand including thumb especially at night. Positive Phalen's sign (flexed hands held against each other's disarm for $30 \mathrm{Sec}$ to one minute) is almost diagnostic of the disease which is later confirmed by nerve conduction study and electromyography.

The treatment options include medical management with medications and splinting and surgical management. Surgical management is offered to those who have failed medical management and not improving with splinting.

The surgical options include open surgical decompression through classic incision, endoscopic technique; ultrasound guided mini open surgery ${ }^{1}$, the Chinese method of using nasal instruments ${ }^{2}$ and a technique which does not involve the use of any instrumentation that is retinaculotomy through the transverse wrist skin crease incision.

The open technique is the standard method of this procedure which has the advantage to see and cut under vision, thereby saving the blood vessels and nerves precisely. However, the standard open technique carries some complications related to the scar and pillar pain, preventing the patient to quickly reassume his/ her daily life activities. Therefore, minimally invasive techniques have been developed by surgeons in order to avoid the risks associated with open technique. Although these mini techniques have got their own disadvantages and risks associated with them like limited field of vision, incompleteness of release and neurovascular injuries, the post op scar tenderness is minimal and return to work is much earlier. 
This study will help in evaluating the outcome of this minitechnique of surgery so that in future it can be adopted as a routine method of performing the procedure for carpal tunnel syndi ${ }_{\text {Date of Submission: 1-1-2020 }}$ to be only a few days off work pro Date of Printing: 31-3-2020

\section{MATERIAL AND METHODS}

\section{Study Design}

Prospective study. This study was approved from the hospital ethical committee. The study was conducted from July 2018 -July 2019.

\section{Inclusion Criteria}

Patients of ages above 15 years and both genders were included.

\section{Exclusion Criteria}

Those having previous operations and very heavy hands were excluded from the study.

\section{Data Collection}

A total of 52 patients were operated and included in the study. The record of these patients was collected on specified Performa. The data was transferred on specified Performa after taking consent from the patient and analyzed.

\section{Surgical Technique}

We used the retinaculotomy method performed by 3 surgeons of the same competence level. This method comprises of a one centimeter transverse skin incision between the proximal and distal wrist creases centered over the line joining the $3^{\text {rd }}$ interdigital space to the crease in between the thenar and hypothenar muscles (Figure 1).

After incising the skin, the flexor sheath in the forearm was cut underneath which median nerve can be seen? Thereafter, the decompression was extended in the proximal and distal directions over a nerve protector guide. One to two skin stitches applied at the end of procedure.

Another challenge to face in this procedure is the release of the distal end of the transverse carpal ligament which is relatively blind to approach. We used the technique of elevating the skin incision with the help of a cat paw and visualize as much possible the transverse carpal ligament and cut under vision.
Rest of the part is sort of blind cutting after feel with a scissor tip in backward dragging of the instrument under TCL and then cut accordingly.

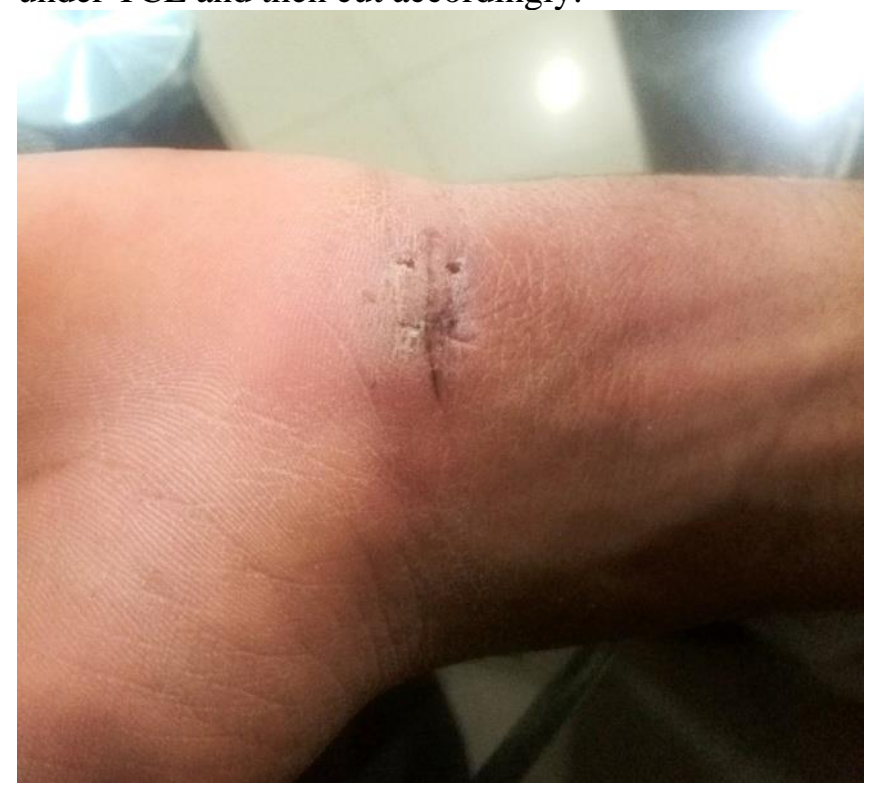

Fig. 1: Transverse $1 \mathrm{~cm}$ skin incision for retinaculotomy (printed after obtaining written consent from the patient).

\section{RESULTS}

\section{Measurement of Pinch Grip Improvement:}

Pinch grip improvement was measured using MRC grading system. A weak pinch grip was supposed to have a power of $4 / 5+$ while normal pinch grip was considered to have $5 / 5$ power.

Pinch grip improved in $15(28 \%)$ of patients by $1^{\text {st }}$ week in $27(52 \%)$ patients by $2^{\text {nd }}$ week, in $38(74 \%)$ patients by the $3^{\text {rd }}$ week and in all $(100 \%)$ patients by $4^{\text {th }}$ week (Table 1$)$.

9\% of patients had scar tenderness which improved by the $4^{\text {th }}$ week in $100 \%$ patients.

Almost all the patients resumed their daily life activities by 4 th week.

Table 1: Number and Percentage of Pinch Grip Improvement Weekly After the Procedure.

\begin{tabular}{|lrr|}
\hline \multicolumn{3}{|c|}{ Total number of Patients Operated 52} \\
\hline Male & 8 & $(15 \%)$ \\
\hline Female & 44 & $(85 \%)$ \\
\hline $\begin{array}{l}\text { Total number of Patients improved by } \\
\left.4^{\text {th }} \text { week in terms of VAS from } 6 \text { to } 1 \text { or } 0\right)\end{array}$ & 8 & $(92 \%)$ \\
\hline
\end{tabular}


Table 2: Pinch Grip Improvement.

\begin{tabular}{|l|c|c|}
\hline & $\begin{array}{c}\text { Number of Pinch Grip } \\
\text { Improved Patients }\end{array}$ & Percentage \\
\hline $1^{\text {st }}$ week & 15 & $28 \%$ \\
\hline $2^{\text {nd }}$ week & 27 & $52 \%$ \\
\hline $3^{\text {rd }}$ week & 38 & $74 \%$ \\
\hline $4^{\text {th }}$ week & 52 & $100 \%$ \\
\hline
\end{tabular}

\section{Complications}

One patient in our study sustained palmer branch of median nerve injury which caused him numbness over the lateral palm. There were no other major complications.

\section{DISCUSSION}

Minimally invasive techniques in carpal tunnel release results in less postoperative pain in the scar and permits early return to work. ${ }^{1}$

Classic carpal tunnel has its own inherited advantages like having ease of doing, large working space with a better visibility of the neurovascular structures which makes it safe avoiding injury to these structures. Apart from this the degree of decompression is optimal. On the other hand, this incision got its own complications in the form of greater degree of scar tenderness, scar hypertrophy and pillar pain. All these factors lead to delayed recovery and delayed assumption of routine activities.

In order to avoid all these complications related to the classic carpal tunnel release incision, mini techniques have been developed. These techniques either use sophisticated equipment like endoscopes, nasal instruments ${ }^{2}$, or retinaculotomy. The easy and inexpensive method is retinaculotomy that's why this technique was studied for results in order to provide the patient minimally invasive treatment with no additional cost. ${ }^{3}$

Carpal tunnel mostly affects women up to $81 \% .^{4}$ This is in comparison to our study, which percent of women affected is $85 \%$. A part from women heavy workers, typists, carpenters and milkmen are mostly affected. The pathophysiology of CTS is complex and results from the interactions of many mechanisms. The pathophysiologic mechanism of CTS is likely attributable to abnormally high carpal tunnel pressure and traction neuropathy. ${ }^{5}$
Up to $92 \%$ patients improved in our study. This is a somewhat better improvement in quoted studies. ${ }^{3,4}$ The visual analogue scale score reduced from 6 to 1 or 0 by the $4^{\text {th }}$ week. This is in accordance to one of international study in which the VAS reduced from 4.5 to 0.5 by the $4^{\text {th }}$ week. ${ }^{2}$ functional outcome also remained good in our study and almost all of the patients were back to work at the end of $4^{\text {th }}$ week. This is in accordance with national and international results. ${ }^{6,7}$

The scar tenderness was in about $9 \%$ patients initially, which later improved in almost all patients. This was reported in one study to be 8.1 percent, ${ }^{2}$ while in another study the scar tenderness remained to be at 3 percent. $^{7}$

There is always a lower risk of scar tenderness and a greater risk of nerve injury following the mini open release. ${ }^{8}$

The pinch grip improvement occurred in our study in almost all the patients at the end of $4^{\text {th }}$ week. This is in comparison to the international data as cited. ${ }^{9,10}$

The methods used to evaluate motor outcome following carpal tunnel surgery included:

i) Measurement of grip and pinch strength with dynamometry or vigorimeter,

ii) Manual muscle strength testing and

iii) Presence or absence of thenar atrophy. ${ }^{11}$ In our study, we used the manual method of muscle testing. It was a subjective feel of the patient initially described as a weakness in the hand, which later improved with the passage of time. The pinch grip was measured in our study using the MRC grading system. Power of 4/5 was considered a weaken grip which later improved to $5 / 5$ in all the patients by the end of $4^{\text {th }}$ week. ${ }^{9}$

\section{Limitations}

Very fatty and thick handed patients could not be enrolled due to difficult approach in these patients. Chances of median nerve injury, neurovascular structures injury and incomplete decompression are much higher than the open procedure. ${ }^{8}$

\section{CONCLUSION}

It was concluded from this study that using the mini technique of retinaculotomy the complications 
associated with the use of the classic open technique can be avoided and patients successfully treated can have an early return to their normal daily life activities. This method should be learnt and used as a routine method of doing carpal tunnel release, especially in those areas where endoscopes are not yet available or those who are not used to it.

\section{REFERENCES}

1. Georgi PG, Vesselin K, Martin A. Orthopaedic Surgery for Carpal Tunnel Syndrome. Clin Surg. 2018; 3: 2245.

2. Chin, et al. The mini incision technique for carpal tunnel release. Medicine (Baltimore), 2017; 96 (31): 2627.

3. Alves MP, Transverse mini-incision for carpal tunnel release. Acta Ortop Bras [Online], 2011; 19 (6): 362-7.

4. Khan, et al. Outcome of open carpal tunnel release surgery: J Ayub Med College, Abbottabad, 2015; 27(3).

5. Aboonq MS. Pathophysiology of carpal tunnel syndrome. Neurosciences (Riyadh, Saudi Arabia), 2015; 20 (1): 4-9.

6. Atroshi I, et al. Outcomes of endoscopic surgery compared with open surgery for carpal tunnel syndrome among employed patients: randomised controlled trial. BMJ. 2006 Jun. 24; 332 (7556): 1473.

7. Vinesh Senan, Balagopalan K, Manesh Senan, Jilsa Sucheendran. Endoscopic vs. Open Carpal Tunnel release. Kerala Journal of Orthopaedics, 2012; 25: 1420.

8. Sayegh ET, Strauch RJ. Open versus endoscopic carpal tunnel release: a meta-analysis of randomized controlled trials. Clin Orthop Relat Res. 2015; 473 (3): 1120-32.

9. Baker et al. Effect of Carpal Tunnel Syndrome on Grip and Pinch Strength Compared With Sex- and AgeMatched Normative Data. Arthritis Care \& Research, December 2013; Vol. 65, No. 12: pp 2041-2045.

10. Atalay NS, Sarsan A, Akkaya N, Yildiz N, Topuz O. The impact of disease severity in carpal tunnel syndrome on grip strength, pinch strength, fine motor skill and depression. J Phys Ther Sci. 2011; 23: 115-18.

11. Geere J, Chester R, Kale S, Jerosch-Herold C. Power grip, pinch grip, manual muscle testing or thenar atrophy - which should be assessed as a motor outcome after carpal tunnel decompression? A systematic review. BMC Muscuoskeletal Disord. 2007 Nov. 20; 8: 114.

12. Ngoc TM, Dung TT, HUU MN, Le KT, Tran Q, et al. The Result of Mini-Open Surgery for Carpal Tunnel Syndrome. Ann Musculoskeletal Med. 2017; 1 (2): 046-049.

13. Newington L, Harris EC, Walker-Bone K. Carpal tunnel syndrome and work. Best Pract Res Clin Rheumatol. 2015 Jun; 29 (3): 440-53.

14. Baker NA, Moehling K, Rubinstein E, Wollstein R, Gustafson NP, Baratz M. The comparative effectiveness of combined lumbrical muscle splints and stretches on symptoms and function in carpal tunnel syndrome. Arch Phys Med Rehabil. 2012; 93: 1-10.

15. Jugovac I, Burgić N, Mićović V, Radolović-Prenc L, Uravić M, Golubović V, et al. Carpal tunnel release by limited palmer incision vs. traditional open technique: randomized controlled tria., Croat Med J. 2002; 43 (1): 33-6.

\section{Additional Information}

Disclosures: Authors report no conflict of interest.

Ethical Review Board Approval: The study was conformed to the ethicalreview board requirements.

Human Subjects: Consent was obtained by all patients/participants in this study.

Conflicts of Interest: In compliance with the ICMJE uniform disclosure form, all authors declare the following.

Financial Relationships: All authors have declared that they have no financial relationships at present or within the previous three years with any organizations that might have an interest in the submitted work.

Other Relationships: All authors have declared that there are no other relationships or activities that could appear to have influenced the submitted work.

Address for Correspondence: Gohar Ali, Department of Neurosurgery Medical Teaching Institute Mardan Medical Complex Mardan KPK - Pakistan Contact Number 00923349300370 Email:docgoharali@hotmail.com 
Gohar Ali, et al

\begin{tabular}{|l|l|l|l|}
\hline \multicolumn{4}{|c|}{ AUTHORSHIP AND CONTRIBUTION DECLARATION } \\
\hline Sr.\# & Author's Full Name & Intellectual/Contribution to Paper in Terms of: & $\begin{array}{l}\text { Signature by } \\
\text { the author(s) }\end{array}$ \\
\hline 1. & Gohar Ali & 1. Proposed topics and Basic Study Design, methodology. \\
\hline 2. & Asghar Ali & 2. Data collection and calculations & 3. Analysis of data. \\
\hline 3. & Mukhtiar Ali & 4. Literature review and manuscript writing \\
\hline 4. & Naeem-ul-Haq & 5. Paper writing & \\
\hline 5. & Salman Mukhtar &
\end{tabular}

Date of Submission: 01-01-2020

Date of Revision: 15-01-2020

Date of Online Publishing: 31-03-2020

Date of Print: 31-03-2020 